\title{
AC 2008-1537: LONGITUDINAL STUDY OF AUSTRALIAN ENGINEERING GRADUATES: PERCEPTIONS OF WORKING TIME
}

James Trevelyan, University of Western Australia

Sabbia Tilli, University of Western Australia 


\title{
Longitudinal Study of Australian Engineering Graduates: Perceptions of Working Time
}

\begin{abstract}
A longitudinal study of a single cohort of university engineering graduates is providing detailed information on the early career of Australian engineering graduates at a time of unprecedented demand for engineers. The graduates respond to web-based surveys every 2 or 3 months and a sub-sample provide more detailed information in telephone or face to face interviews. The participation rate was initially $60 \%$ and is still at above $40 \%$ after 12 months. The study aims to collect information on the work actually performed by the graduates, their perceptions on the amount of time they spend, how they learn the required skills and knowledge, training and professional development that they receive, and perceived gaps in their knowledge. We also aim to understand more about their career trajectories in the early years. Early surveys reveal the types of work performed by graduates in the first year of their career and some information about their early career learning. The paper provides an analysis of data on graduates' perceptions of the time they spend on different aspects of their work. This reveals that about $60 \%$ is spent on interactions with other people either face to face, on the telephone, or through written documents, showing the dominant role of social interactions in engineering practice.
\end{abstract}

\section{Introduction}

Unfortunately there are few reliable reports of research on engineering practice ${ }^{1,2}$. Very few observations have been reported, for example, on the actual work performed by engineers, technical managers, planners, technologists and technicians. Certain processes in engineering practice such as design and project management have been extensively studied, yet many other aspects such as maintenance have hardly received any attention at all. This is all the more surprising given the extensive debates and written literature on engineering education. An accurate account of engineering practice could help educators explain the relevance of coursework to students, helping to provide appropriate motivation for learning. Such an account may also reveal opportunities to improve curriculum design.

This paper builds on results from an ongoing empirical study to establish a systematic framework to explain engineering practice in the majority of engineering disciplines based on 70 semistructured interviews, extensive experience and confirmatory field studies ${ }^{3}$. Both the framework study and the longitudinal study are part of a larger Engineering Learning and Practice Research project involving 4 academics and 15 research students working on detailed, systematic examination of engineering work in several disciplines and industry sectors. The framework study uses qualitative ethnography using semi-structured interviews and some limited field studies $^{2}$. Typical interviews consist of open-ended questions that explore perceptions of educational experiences, the subject's career background and daily work. Further questions explore perceptions of commercial issues such as costs and the financial development, teamwork and subordinates, the market for engineering services and products, human resource issues in organizations, information resources and other aspects of engineering work. The participants 
represent a range of engineering disciplines, industries, ages and years of professional experience.

The framework study revealed that engineering work is very complex, and also showed that technical and social skills are inextricably intertwined ${ }^{2}$. One example is obtaining technical and planning information from diverse sources and assembling the information in a logical way to present to other people (both technical and non-technical). Another example is knowing which tools, equipment, manufacturing or assembly methods, jigs, fixtures, temporary supports, formworks etc (which are seldom shown in drawings) are needed on a construction site and arranging for all of this to be delivered on site and erected at the appropriate time. It is just assumed the engineer will know what is needed and when, and whom to ask when he or she does not know.

The framework study also shows that engineers need to acquire a large amount of know-how, very little of which is learned at university. Most of this is a combination of generic and technical skills, as in the example given above. The generic skills can be taught (health and safety, communication, meeting skills etc). However, some know-how is difficult to learn because of the nature of the material. Some technical knowledge is minute in detail and vast in quantity, for example, knowledge of components and materials; intrinsic properties of components and materials; applications; performance properties, particularly in combination with other components and materials; where to purchase them; and what level of support is required and available. This does not lend itself to being easily learned. Much of this knowledge is not written down because it is tacit knowledge and so cannot be easily taught using conventional methods. An example is assessment of normal working standards and production faults or defects: is the straightness of a beam acceptable for its application? Is the painting on the cabinets done to an acceptable standard? Such standards are difficult to document and often only exists in the minds of people.

There has been some research on the links between what is taught in engineering institutions, what graduates learn early in their careers and what training engineers undertake while in the workforce. For example, Martin et $a l^{4}$ surveyed graduate perceptions on how well they were prepared for their careers and others have written on the 'dissonance' between education and practice $^{5,6}$. While graduates felt confident of their technical abilities, they had experienced weaknesses in communication and team working skills.

At the same time, however, there have been many concerns expressed by employers on the apparent gap between engineering education and professional practice ${ }^{7-9}$. These concerns continue even after fundamental changes to accreditation criteria have been introduced worldwide. In a survey to assess the effects of these changes, only about $50 \%$ American employers thought that engineering graduates understood the context and constraints that govern engineering, and there was a majority assessment that graduate understanding had declined in the last decade ${ }^{10}$. This agrees with persistent feedback from employers in Australia that graduates lack appreciation of fundamental knowledge and engineering courses are misaligned with engineering needs. A survey of industry requirements for engineering education in Britain found evidence of skill deficits and concern that "the grade of degree awarded can be a poor indicator of a graduate's actual abilities"11. Employers expressed "a need for enhancing courses in terms 
of their development of practical skills but not at the cost of losing a strong theoretical base". However, it is not clear what is meant by 'practical skills'.

A clearer understanding of engineering practice and early career trajectories might help young people with career choices. Without a clear understanding students choosing to study engineering may be doing so based on misunderstandings of their future career and what they will be doing after graduation. This may result in students who may be well suited to engineering work failing to consider this profession as a career, while others who may be less suited to this work enter study and then leave the profession. Traditionally, students excelling in science and maths have been steered toward engineering. However, is high-level ability in science and maths a sufficient or necessary condition for producing a competent engineer? Are other skills/attributes equally or more desirable?

Understanding more about the transition between engineering education and practice could also provide highly relevant guidance for curriculum development. On-the-job learning and industry specific training will always be needed but this takes time. A detailed understanding of engineering practice in the first year could be helpful in helping graduates make an easier and more productive transition into their careers and also help employers understand which training will be most effective.

There is a clear need for empirically based research to fill these gaps in our understanding of the relationship between engineering education and practice by studying novices: graduate engineers in the first few years of their career.

Need for a longitudinal study

A longitudinal study of one or more cohorts of engineering graduates could provide useful insight on these issues.

An extensive literature search revealed five recent longitudinal studies of engineering graduates $^{12-16}$.

Sheppard et $\mathrm{al}^{12}$ are undertaking an interdisciplinary longitudinal study of the engineering student experience using several research approaches. As part of their study they plan to follow the transition to the workforce of some of the 48 participants as they move from "the end of their junior year through their first two years post-B.S. With this cohort, we will focus on the critical transition from undergraduate education to either the workforce or graduate school."12. While this is a very interesting and comprehensive study of engineering students in the US, its main focus is the engineering student experience, not what engineers do in the workforce.

Western et $a l^{13}$ examined engineering, law and medicine graduates over a 30 year period. Their particular interest was how participant attitudes to the profession, knowledge, service and autonomy change over time. While this study gives very interesting insight into how attitudes of the three groups of professionals have altered over time, it does not examine the detail of what engineers do in their job. 
Boxall and Steeneveld ${ }^{15}$ base their study on engineering consultancies. Their work examines the influence of human resource strategies on competitive advantage and so is focused on engineering business activity at the firm level, rather than at the level of individual engineers. Conclusive results were difficult to reach because there were several other factors differentiating the small number of firms examined apart from human resource strategies.

Ashorth et ll $^{14}$ examine the socialisation process of professionals in the workforce, including graduate engineers. Again, it is an insightful study, but it does not inquire deeply into engineering practice.

Eraut $^{16}$ follows a group of engineering graduates seeking chartered status along with a group of nurses and a group of accountants to understand the processes involved in workplace learning, particularly implicit learning on the job. So far this study has not revealed much about the detailed career trajectories of a particular occupational group. By using interviews and field studies his team acquired rich data from both the participants and their employers (at considerable cost). From this data he proposes three dimensions of professional practice: elements, time, and survival. The elements are:

i. Assessing clients and/or situations and continuing to monitor them

ii. Deciding what, if any, action to take, but immediately and over a longer period (either individually or as a leader or member of a team)

iii. Pursuing an agreed course of action, modifying, consulting and reassessing as and when necessary

iv. Metacognitive monitoring of oneself, people needing attention and the general process of the case, problem, project or situation.

The time dimension provides for instant reflex actions (short term), and deliberative diagnosis and action with review and reflection (long term). The survival dimension involves the construction of learned routines that become tacit over time enabling the professional to respond quickly to situations with increasing responsibility and complexity.

None of these studies provide detailed information on what the graduates are actually doing in their work and hence can provide information to evaluate in detail the strengths and weaknesses of their undergraduate education. However, they provide guidance on the strengths and weaknesses of different empirical approaches, and useful alternative frameworks within which to view the detail of early career engineering practice.

\section{Methodology}

The aim of this study is to understand more about engineering as it is practised in the first few years of an engineering career and how young engineers develop their abilities after graduation. We would like to learn about engineering as it is practised in more detail than previous studies and with a larger sample of graduates.

An underlying assumption that has informed our thinking about engineering work is that training and experience is an essential component of the first few years of an engineering career. This assumption is based on data from the framework study interviews in which all participants said 
that it took between two and five years for a novice to become 'competent'. While each participant had a different interpretation of competence, all identified this early career period as important. We are interested in several issues:

- what novices do,

- the kinds of training they receive,

- what they learn by other means,

- adjustments they have to make,

- perceived deficiencies in undergraduate education, and,

- career trajectories.

The issues we want to pursue in this study can be divided into questions about work and questions about training.

We share the view commonly held by sociologists that work is socially constructed, and our understanding of what constitutes work is influenced by social, economic and institutional factors $^{17,18}$. (In doing so, we reject the positivist notion that it is possible to measure or record an objective reality of work engaged in by our study participants.) Also, work can be paid, unpaid, formal and informal, and to understand the work of our participants we cannot just reduce their activities to wage labour explained by the forces of demand and supply. To answer our research questions we will ask participants, as is elaborated below, for their perception about what work/activities they engage in as part of paid employment and what other work/activities they engage in to advance their skills, knowledge and abilities in paid work. We will also seek limited information on their aspirations and the social context of their work. We understand that we can only have a comprehensive understanding of engineering work when we have a clearer picture of the context as well as the content of work activities. At this early stage of the study we can answer our questions by looking in more detail at the content of engineering work rather than why and how participants construct their concept of work.

Our thinking about training has Human Capital Theory as its foundation. However we recognise that "Training is, after all, a contested organizational activity, situated in a complex set of political and institutional arrangements" ${ }^{, 17}$ and employee and employer behaviour is not as rational as the human capital framework assume ${ }^{17}$.

In this paper we address the first issue: what do novices do and how much of their time they spend on different aspects of their work.

\section{Method}

The study has two aspects: surveys and interviews. The scope has been constrained by limited resources available for the study.

We started a pilot study in 2006 with 14 former graduates with between 2 and 5 years work experience to help develop web-based survey methods and questionnaires. Of these 9 are still participating after 10 surveys. Responses from the pilot study group help us refine the survey questions in advance of the main study surveys. 
The main study commenced in 2007 with 192 graduates from the 2006 graduating cohort. We managed to recruit around $60 \%$ of the overall graduating cohort from the faculty including civil, electrical, electronic, environmental, information technology, materials, mechanical, mechatronics, oil and gas, petroleum, resources and mining systems engineers. From the pilot study we found that at least two class appearances are needed in person to recruit a significant percentage of graduating students. One group, software engineering, had no formal classes in the last few months of their course so we resorted to e-mail, but without success. The participation rate for electrical and electronic engineers is also less than the other disciplines for similar reasons. We also appeared at student social functions and graduation ceremonies to reinforce the message. The number of responses from four surveys through the first year has been 162, 160, 152 and 120, though the last took place through December, a difficult time to solicit e-mail responses.

We will continue to follow this cohort for as long as we obtain useful data: we will terminate the study after five years. Many graduates enter graduate development programmes and then change jobs after 3 years so that is a critical time to monitor their career trajectories.

The participants are surveyed electronically 4-6 times annually, although not all participants respond to every survey, nor do they answer every question when they do respond to a survey. Electronic surveys can provide a higher response rate than paper-based surveys ${ }^{19}$. Each invitation to participate is a personally addressed E-mail message generated from purposedesigned software. Each of the surveys has quantitative and qualitative questions. (The questions for the first year of the survey are available on request.) Apart from the questions collecting details about job history, most of the qualitative questions asked in the first 12 month period are exploratory in nature (for example, questions about gaps in undergraduate education). We anticipate that the responses to these questions will give us information to formulate additional hypotheses which we can then test with quantitative questions in the second and subsequent years of the study.

Quantitative questions will help triangulate findings from the framework study. This study provided descriptors for aspects of engineering practice using terminology that is meaningful in any discipline ${ }^{3}$. For example, one of the 85 aspects is "Reduce costs (either in design, construction, operations or maintenance) use detailed technical and business knowledge to achieve required cost reductions while minimizing performance loss". Not all engineers work in every aspect, however, each aspect is supported by detailed evidence from the study. Some aspects have been part of every participant's work, such as "Coordinate work of peers, subordinates and superiors; perform technical checks on work, watch for roadblocks, may provide advice and feedback, may review technical competence, may assess training needs, provide informal training when appropriate". The aspects are not exclusive: for example one could be coordinating others as part of a design or review task. The aspects can be grouped in different ways, for example "Coordinating and working with others" and "Engineering management processes" and "Technical test, inspection, measurement, review and checking".

Using these terms we can ask novices meaningful questions about their work, the skills and knowledge required, and also the amount of time spent working on each aspect. The value of the framework study descriptors is that the questions posed in those terms should be equally 
meaningful in different engineering disciplines. By asking them to describe any other aspects of their work not covered by the framework-derived descriptors, we can test the framework for completeness. Respondents who cite "other" aspects inform us that the framework is either incomplete, or is not described fully enough. Time estimates are subjective but, when averaged over a large sample, could provide strong evidence on the relative prominence of different aspects of practice in different engineering disciplines.

This survey will also allow us to acquire a detailed profile of the experience growth of a significant sample of novices.

We aim to conduct qualitative interviews with 10 percent of participants either by phone or in person. Participants will be asked open-ended questions about their work, in a similar fashion to the framework study. These interviews will be used to confirm data from the surveys and provide more detailed data on any unexpected issues in written survey responses.

Initial Results

The longitudinal study commenced in April 2007 and so far participants have responded to four surveys. In April 2007130 said they were employed and of the remaining 32 about two thirds were in the process of obtaining work (e.g. waiting for residence permits, confirmation from employers) with the remainder travelling or on national service (for a few international students). Only three were still looking for work. The study has so far been conducted at a time when engineers were in extremely short supply: obtaining engineering employment has not been as easy for a long time. In June 2007, 140 respondents said they were working, two were seeking work, and the remaining respondents were pursuing further studies or travelling. In subsequent surveys the proportion working has increased slightly with a few changing jobs. At the third survey (September 2007) novices were working an average of 49 hours per week with an average of 7 hours unpaid overtime and 4 hours of work-related social activities each week.

The framework study provided 85 engineering practice descriptors which can be grouped into categories as follows:

1. Managing self and personal career development (8 descriptors)

2. Coordination, working with other people (16)

3. Engineering processes, project and operations management (13)

4. Financial processes (6)

5. Procurement, buying products or services (3)

6. Human resource development, training (4)

7. Business development or marketing, selling products or services (11)

8. Technical work, creating new concepts, problem solving, programming (13)

9. Technical reviews, checking, testing and problem diagnosis (10)

10. Hands-on technical work, construction or repairs (1)

By counting interview references, Trevelyan ${ }^{2}$ concluded that item 2 was the most prominent aspect of engineering practice (27\% of references) followed by items 3, 9 and 8 . However, not one of the engineers interviewed for the study specifically mentioned coordination (aspects of item 2): instead each contributed fragments through their stories. The process seems to be such a routine and mundane part of engineering practice that it is tacit, practiced without conscious 
awareness. Given that we can only ask novices about aspects of engineering practice that are immediately meaningful to them and we have to restrict the number of questions in each survey, we have started by grouping aspects of engineering practice in a different way. In the second survey we asked graduates to estimate the time spent working on these different aspects. We grouped them into interactions with people face to face, through documents, and interactions with hardware and with abstract systems and data, as shown below.

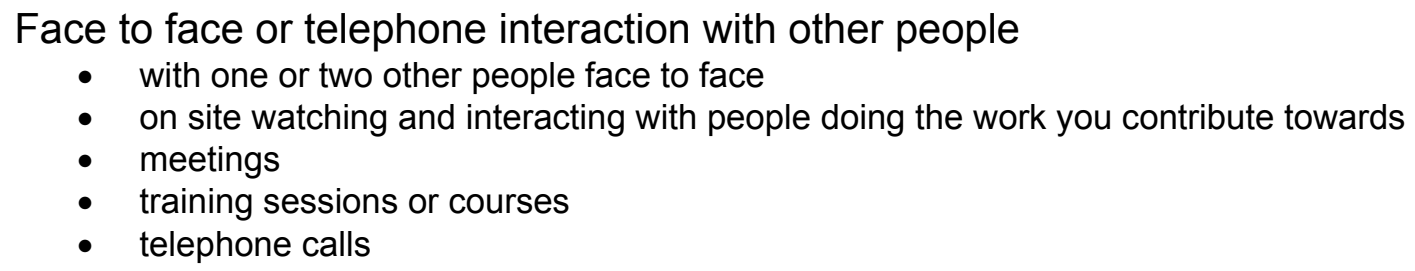

Interactions with people through text or documents (including reports, specifications, drawings, plans, schedules, procedures, work instructions, operating or maintenance manuals, bills of materials, budgets, tender documents, invoices, contracts etc.)

- text messaging, chat

- e-mail correspondence, queries

- $\quad$ reading or checking formal documents

- writing, preparing formal documents

Interacting with systems or abstract data

- searching for information on internet, in filing systems, databases, libraries etc.

- calculating, modelling, simulation, data analysis.

- designing, drawing, creating software code.

- debugging machinery, systems or software code.

Interactions with hardware, site work

- operating, testing, working hardware or systems

- surveying, measuring, inspecting, or observing on site

- maintaining the computers \& filing systems you use in your work, installing or updating software etc.

- other hands-on work with equipment hardware, construction etc.

- searching for misplaced items.

Respondents were asked to choose from the following: none, $<2 \mathrm{hrs}, 2-5 \mathrm{hrs}, 5-15 \mathrm{hrs}$, or $>15 \mathrm{hrs}$ (or no selection at all). Responses were interpreted as $0,1,3,7$, or $15 \mathrm{hrs}$ respectively. The total for different respondents varied (both as an artefact of the discrete choices and also possible overlap, e.g. calculating while interacting with people face to face). Therefore the time fraction for each category was calculated, and the resulting fraction averaged across groups of respondents in each discipline shown in table 1 . Some respondents may have interpreted $<2 \mathrm{hrs}$ as indicating a nil response and therefore percentages at the low end should be treated as negligible time. For each of the technical activities the respondents were also asked where they learned the required skills and knowledge: Learnt at Uni/School, learnt from colleagues, learnt from training course, learnt elsewhere, or self-taught.

The results are shown in the following tables. Table 1 shows the average time on each aspect for the major discipline groups. The "other" group consisted of environmental engineering, oil and gas engineering, petroleum engineering and mining systems engineering. Each group consisted of between 30 and 40 respondents. 


\begin{tabular}{|rccccccc|}
\hline & Civil & Mechanical & $\begin{array}{c}\text { Electrical } \\
\text { Electronic }\end{array}$ & Mechatronics & Others & $\begin{array}{c}\text { Pilot } \\
\text { Study }\end{array}$ & Ave \\
Face to face informal & $=13.1=$ & 13.1 & 9.5 & 11.4 & 11.6 & 10.8 & 11.6 \\
Write documents & 8.7 & 10.2 & 12.1 & 10.9 & $=13.4=$ & 10.4 & 11.0 \\
\hline Calculation, simulation & 11.6 & 8.7 & 3.3 & 7 & $=17.8=$ & 6.9 & 9.2 \\
Searching for information & 6.1 & 8.7 & $=12.2=$ & 7.9 & 6.5 & 7.9 & 8.2 \\
\hline E-mail & 8.3 & 8.4 & 8 & $=8.9=$ & 7.4 & 7.8 & 8.1 \\
\hline Read, check documents & 4.5 & 6.2 & $=8.4=$ & 7.6 & 7.2 & $=8.8=$ & 7.1 \\
Meetings & 6.9 & 6.1 & $=7=$ & 5.3 & 5.9 & $=8.5=$ & 6.6 \\
\hline Design, coding & 5.8 & 6.5 & 6.2 & $=8.6=$ & 4.4 & 7.4 & 6.5 \\
\hline With people on site & $=8.8=$ & 4 & 4.4 & 4.6 & 4.1 & 6.6 & 5.4 \\
Training sessions & 6.4 & 6.1 & $=6.8=$ & 3.6 & 6.5 & 1.8 & 5.2 \\
\hline Phone & 3.3 & 3.7 & 4.8 & 3.3 & 2.6 & 2.7 & 4.0 \\
\hline Operating, testing & 2.6 & 3.3 & $=3.8=$ & 2.9 & 2.3 & $=4.6=$ & 3.3 \\
\hline IT, filing maintenance & 1.1 & 1.9 & 4.1 & $=4.5=$ & 1.6 & 2.2 & 2.6 \\
\hline Hands on work & 3 & $=3.5=$ & 2.4 & 1.9 & 1.2 & 2.7 & 2.5 \\
\hline Debugging & 0.5 & 1.8 & 1.7 & $=3.8=$ & 1.6 & 4.3 & 2.3 \\
\hline Text messages & 2.2 & 2.2 & 1.8 & 3.1 & 2 & 1.5 & 2.1 \\
\hline Searching for lost items & 0.6 & 1.3 & 1.1 & 0.9 & 0.5 & 2 & 1.1 \\
\hline
\end{tabular}

Table 1: Average perceived percentage of working time spent on different aspects of engineering work at 6 months after commencing work. The highest figures have been highlighted with "=" markers. Note that the pilot study group are predominantly mechatronics.

\begin{tabular}{|rcr|}
\hline & Ave & Cum \\
\hline Face to face informal & 11.6 & 11.6 \\
With people on site & 5.4 & 17.0 \\
Meetings & 6.6 & 23.6 \\
Training sessions & 5.2 & 28.8 \\
Phone & 3.3 & 32.1 \\
Text messages & 2.1 & 34.3 \\
E-mail & 8.1 & 42.4 \\
\hline Read, check documents & 7.1 & 49.5 \\
\hline Write documents & 11.0 & 60.5 \\
\hline Searching for information & 8.2 & 68.7 \\
\hline Calculation, simulation & 9.2 & 77.9 \\
\hline Design, coding & 6.5 & 84.4 \\
Debugging & 2.3 & 86.7 \\
\hline Operating, testing & 3.3 & 89.9 \\
\hline Survey, inspection, observation & 4.0 & 93.9 \\
\hline IT, filing maintenance & 2.6 & 96.5 \\
\hline Hands on work & 2.5 & 99.0 \\
\hline Searching for lost items & 1.1 & 100.0 \\
\hline
\end{tabular}

Table 2: Average perceived percentage of working time in major groups with cumulative percentage. This reveals about $60 \%$ of time spent interacting with other people either directly or through documents. 
The pilot study group consists mainly of mechatronics engineers with between 2 and 5 years experience. There is remarkable similarity in the result profile of this group with the mechatronics novices. The results show significant differences between the discipline groups. Civil novices spend more time on site. The "other" group spend more time on calculation, simulation and analysis. Mechatronics novices seem to do more design and software work and receive less training. Design is a relatively small component of work for all the other groups.

We can be reasonably assured that this data covers nearly all aspects of the novices' work because we also asked respondents to indicate if there were other aspects that we missed. However, there were a very small number of responses to these questions, the only significant one being extensive data entry for one respondent.

The most significant result is that around $60 \%$ of the time is spent on interacting with other people, of which nearly two thirds is direct interaction. This is surprising as many anecdotal sources suggest that an engineering career is predominantly technical work at first, followed by increasing management-related activities. We have avoided using the term "management" because it can take different meanings in different contexts. This data presents further strong evidence that social interactions dominate technical activities even in the first year of engineering practice.

The reliability of the numerical results could be questioned. It is not always easy to estimate the time spent each week on different aspects of work especially as en engineer's work pattern can change daily. However, the average total hours reported in the time perception data is 55 hours per week which is close to the average reported total weekly working time (42 hours paid, 7 hours unpaid overtime). There is some possibility of overlap, for example, a meeting could be held on site, and this could explain why the total perceived time is slightly more that the weekly working hours. Also, the small number of discrete number of responses and their interpretation can influence these results. There is considerable variation in the individual responses, but it is interesting that the data showing least variation is the time spent working informally face to face with other people.

Qualitative Work Descriptions

We also asked participants to describe their work in qualitative terms, but most of this data is still to be analysed. We present some examples selected at random below to illustrate the kinds of responses. Identifying details have been removed or changed to protect participants. The text appears just as they entered it: no grammatical or spelling corrections have been made. There were two relevant questions:

a) The organization/project you are now working with (type of business, type of section where you work, main project you are working on).

b) Tell us what you have been doing in your job in the last month.

Applied Ocean Science ("other" group)

a) I work in a large engineering consultancy. I work in the coastal and ocean group of the Infrastructure group. The main project I am working on is the Esperance Town Beach rejuvenation. 
b) Numerical modelling for new canal systems. Research and numerical modelling for town beach rejuvenation projects. Training (reading manuals etc).

\section{Civil 1}

a) A large multidisciplinary engineering consultancy with around 130 offices worldwide. They have a rotational graduate development program and i am currently employed as a structural engineer in their TW division. TW are concerned with the maintenance, analysis and upgrade of offshore platforms and an onshore LNG Plant. It is primarily Oil \& Gas design and analysis. b) I am curently working on platform analysis and redesign of specific segments and modules as the platform topside is constantly upgraded.

\section{Civil 2}

a) Current employer: Iron Ore Company, specialisation: Mining Position: Graduate civil engineer. I am currently working on a port upgrade project. The project is focussed on uprgrading the existing port so as to increase annual iron ore processing capacity. I have been placed with the consultant design team that are employed by the company to gain design experience and familiarisation with the project. I am currently involved in detailed design for the civil works that are part of the port upgrade. The focus of my design work is in the marine section at the moment with a special focus on the jetty extension.

b) This last month I have been placed in with an Engineering Procurement Construction Management team who do the design engineering for the project I am working on. As my company don't do any design work in house I have been placed in with the EPCM to gain design experience and understand the process that goes into preparing a design package for a project. I am working on various pieces of design work both individually and in a team and complete a multitude of tasks from design calculations to composing scope of work documents. In addition I have had the opportunity to attend various meetings discussing progress of the project, design options, scheduling and costing.

\section{Electrical 1}

a) Electricity utility electrical engineering electricity networks business.

b) Project estimates (overhead transmission lines and underground cables), clearance and easement calculations.

\section{Electrical 2}

a) Oil and gas company

b) I've been involved in technical integrity improvements for offshore \& onshore facilities. Also have been involved in project controls/managment duties.

\section{Information Technology 1 (part of Electrical group)}

a) I am currently seconded to a water utility, and placed within the SAP Application Support team. The client has a SAP system providing business supports and the job of the team is to support the system. This involves from fixing software glitches in the system to implementing a system upgrade. Currently,my main work is to fix the software glitches in the SAP Portal area that has been identified by the business analysts. I am also somewhat involved in the closing stages of a Single-Sign-on implementation project. In both scenarios I am required to understand the client's business processes and write software codes that will achieve their requirements. 
b) Involved in various programming projects that is currently being implemented on site. In addition to pgramming new codes,communicating ideas and solutions to clients and colleagues is done on daily basis and is an integral part of the job.

Mechanical 1

a) Oil and Gas company, working on a sub-sea gas project in their project services department.

b) Mainly working on budgets and interacting with people to get the appropriate information from them.

\section{Mechatronics 1}

a) Oil and Gas company Chevron R\&D Project Coordination

b) Assisting with work scope development for a number of Subsurface projects. Assisting with applications for government grants for R\&D. Developing a Technology Portfolio Management Process and preparing for presentation of the process to the Leadership team.

The qualitative responses provide useful illustrations of the important of social interactions. For example,

"I am required to understand the client's business processes"

"I am working on various pieces of design work both individually and in a team", and, "interacting with people to get the appropriate information from them".

Many of the graduates in this study have studied combined degrees, for example commerce and engineering or science and engineering over 5 or more years of undergraduate study. It may be possible to analyse the qualitative data to see whether there is a consistent difference in the nature of the work they perform. However, as shown above, the quality of responses varies enormously (many do not respond to some of the questions) so it is not possible to predict how much can be learned from detailed analysis of qualitative responses yet.

\section{Conclusions}

The results cannot be generalized in detail because the study includes graduates from a single institution in one country. However, even with this restricted scope the study raises important questions about the kind of work that engineers perform.

The results agree surprisingly closely with qualitative data from the framework study which provided strong evidence that around $60 \%$ of the work of engineers involves interactions with other people. While the framework study involved engineers with a wide range of experience, this study has provided data from graduates. More work is required but these results suggest that problem solving, design and calculation features less prominently than interactions with other people. There is little variation in this component between discipline groups, but there are significant differences in the distribution of technical work between discipline groups.

Even though these are preliminary results on a limited sample of graduates, they challenge widely held assumptions about engineering practice and expose limitations of the undergraduate engineering curriculum. For example, in response to a series of questions about time spent on checking and reviewing documents, measurement and survey work, and inspection of completed 
work, one respondent wrote "These questions above all feel like 'real world' questions, why do they make sense now, but I have never been exposed to this kind of stuff at uni??"

A companion paper on the framework study explores possible implications for engineering education arising from this research ${ }^{3}$.

\section{Acknowledgements}

The authors would like to acknowledge the support of the Faculty of Engineering, Computing and Mathematics and the School of Mechanical Engineering for this study, as well as private donations. The authors would also like to acknowledge contributions from colleagues in the Engineering Learning and Practice Group and Dr. Lesley Jolly of the University of Queensland for invaluable help with survey design and methodology.

\section{References}

1. J. P. Trevelyan and S. Tilli, Published Research on Engineering Work. Journal of Professional Issues in Engineering Education and Practice, 2007. Vol. 133, No. 4, pp. 300-307.

2. J. P. Trevelyan, Technical Coordination in Engineering Practice. Journal of Engineering Education, 2007. Vol. 96, No. 3, pp. 191-204.

3. J. P. Trevelyan. A Framework for Understanding Engineering Practice. in American Association for Engineering Education (ASEE) Annual Conference. 2008. Pittsburgh.(submitted for review).

4. R. Martin, B. Maytham, J. Case and D. Fraser, Engineering graduates' perceptions of how well they were prepared for work in industry. European Journal of Engineering Education, 2005. Vol. 30, No. 2, pp. 167180.

5. N. S. Edward and J. C. R. Middleton. Occupational Socialisation -- a New Model of the Engineer's Formation. in International Conference on Engineering Education. 2001. Oslo, Norway.Session 8D2 pp1122.

6. E. Baark, New Modes of Learning in Services: a Study of Hong Kong's Consulting Engineers. Industry and Innovation, 2005. Vol. 12, No. 2, pp. 283-301.

7. S. Florman, Non-technical studies for engineers: The challenge of relevance. European Journal of Engineering Education, 1997. Vol. 22, No. 3, pp. 249-258.

8. C. Dillon, Engineering education: time for some new stories. Engineering Science and Education Journal, 1998. Vol., No. August, pp. 188-192.

9. L. Pascail, The emergence of the skills approach in industry and its consequences for the training of engineers. European Journal of Engineering Education, 2006. Vol. 31, No. 1, pp. 55-61.

10. L. R. Lattuca, P. T. Terenzini and J. F. Volkwein, Engineering Change: A Study of the Impact of EC2000. 2006: ABET. http://www.abet.org/papers.shtml, accessed.

11. N. Spinks, N. Silburn and D. Birchall, Educating Engineers for the 21st Century: The Industry View, Henley, England: Henley Management College, 2006.

12. S. Sheppard, C. Atman, R. Stevens, L. Fleming, R. Streveler, R. Adams and T. Barker. Studying the Engineering Student Experience: Design of a Longitudinal Study. in American Society for Engineering Education Annual Conference \& Exposition. 2004.Paper 1736.

13. J. Western, M. Haynes, D. A. Durrington and K. Dwan, Characteristics and benefits of professional work: Assessment of their importance over a 30-year career. Journal of Sociology, 2006. Vol. 42, No. 2, pp. 165188.

14. B. M. Ashforth, D. M. Sluss and A. M. Saks, Socialization tactics, proactive behavior and newcomer learning: Integrating socialization models. Journal of Vocational Behavior, 2007. Vol. 70, No. 3, pp. 447462.

15. P. Boxall and M. Steeneveld, Human Resource Strategy and Competitive Advantage: A Longitudinal Study of Engineering Consultancies. Journal of Management Studies, 1999. Vol. 36, No. 4, pp. 443-463.

16. M. Eraut, Learning from other people in the workplace. Oxford Review of Education, 2007. Vol. 33, No. 4, pp. 403-422.

17. D. Bills, Introduction: The Sociology of Job Training, in Research in the Sociology of Work: Vol 12 The Sociology of Job Training: . 2003. p. ix-xvii. 
18. R. Taylor, Extending conceptual boundaries: work, voluntary work and employment. Work, Employment and Society, 2004. Vol. 18, No. 1, pp. 29-49.

19. C. Frankfort-Nachmias and D. Nachmias, Research Methods in the Social Sciences. 4th ed: St Martin's Press, 1992. 